\title{
Research of Enterprise Visual Identity Design on Urban Development
}

\author{
Daizhen Wei \\ Department of Art and Design \\ Yantai Nanshan University \\ Yantai, China
}

\begin{abstract}
Visual identity design is to use visual signs to convey enterprise information and promote the development of enterprises, which will promote urban construction. Under the premise of investigation on enterprise visual identity design, it is necessary to make specific solutions such as attach great importance to the development strength of visual identity design and make efforts to improve the comprehensive quality of designers, and put forward concrete implementation ideas about all elements of visual identity design to promote urban development.
\end{abstract}

Keywords-visual identity design; market positioning; investigation

\section{INTRODUCTION}

The development of enterprises plays a decisive role in urban image construction. Visual identity design is to use visual signs to convey enterprise information and promote the development of enterprises. And there is no doubt that the development of enterprises can promote urban construction. Some people think that CI strategy of enterprises is the application of urban image construction in urban region. Although it seems that this kind of opinion has some biased errors, we cannot deny the decisive role that the development of enterprises plays in urban image construction.

\section{FUNCTIONS OF ENTERPRISE VISUAL IDENTITY}

\section{A. Make the Market Position of Enterprise Become Clear}

Visual identity system embodies the parts that have the most communication competence and appeal in enterprise identity system and makes them accepted by the masses. It will produce the most effective and direct functions on external publicity and corporate identity by using systematic and unified visual sign system to make audiences realize rapid identify and cognition of enterprises or brand images of products. Visual identity design is the halo for enterprises to create business atmosphere, can effectively influence the evaluation of people for enterprises and their products and make its unique design different from other enterprises; visual identity can let enterprises clearly know their market positioning. It belongs to an important part of the intangible asset of an enterprise, provides strong guarantee for enterprises to participate in market competition and then strengthen the competitive advantage in market.

\section{B. Make the Development of Enterprise Economy Get Promoted}

For both manufacturers and designers, the practical purpose of visual identity design is showed on economic benefit. When design gradually becomes popular, its economical feature is highlighted. Commodity circulation is a form of economic activity and the market is the channel of commodity circulation. Enterprises must make their products realize certain economic benefit through market sales, complete economic accumulation and then continuously expand reproduction. As an effective way to participate in market competition and improve economic benefit, design has become an important means for enterprise, city and country to seek for development.

\section{Make Urban Culture Reappear}

Urban culture is unified synthesis formed in city that different groups act on creativity and results of urban society and interact and integrate with regional culture. Enterprise is the main force in this group. The development of enterprise culture will directly relate to the creation of cultural atmosphere of the city. As middle environment, urban culture provides background and source for the forming and development of enterprise culture. After groups of enterprise culture are formed, they integrate with urban culture and bring new ideas and motive force of development and form the situation that both of them integrate with each other, learn from each other's strong points to offset each other's weakness and commonly prosper. Each enterprise in the city shows enterprise culture in the visual communication forms that use various media as carriers. They have visual image design of their own. Brand image can represent urban image to a great extent, so visual identity design of enterprises directly presents urban image to the masses and deeply embodies cultural connotation of the city. 


\section{ANALYSIS ON THE DEVELOPMENT OF URBAN VISUAL IDENT ITY DESIGN}

\section{A. Non-standard Phenomenon Exists When Enterprises Use VI.}

In the process of application, many non-standard usages exist in some enterprises. For example, they randomly change colors of logos and do not implement according to specified standards when they place logos on different media or materials, which lead to the fact that the logos are out of shape. When this kind of problems appears, enterprise management level cannot realize the severity. In their opinions, if they do VI, effects will be achieved. Of course, in some big enterprises or organizations, this situation will seldom happen. In this kind of company, there is an advertising department and it is mainly responsible for consulting with advertisement companies, choose proper companies to do advertising program for them, check proposals of advertisement companies, supervise and implement advertising program and evaluate advertising effects, etc. Although this situation is more optimistic than the former, this pattern is at an early stage, and needs regulating. The quality of actual operation of employees also needs improving.

\section{B. Employees Have Deviation in Understanding VI Design.}

Some designers think: Logo design is the main part in doing a set of VI. After the logo is finished, other links will be very easy. They can even find a template to directly apply mechanically and use new logo to replace. They completely focus on logo design without paying attention to the functions of other design elements and without realizing that VI design is organic and complete. Each visual element should well embody the principal part of enterprise image design. Ignoring the whole and persisting old ways will inevitably make enterprise image design become empty talk.

\section{The Implementation and Using of Visual Identity Elements are Unfixed.}

Some enterprises randomly change visual images that have entered the market. They change the forms of packaging and colors of the logo every now and then. Visual identity design is image design that can enter the market after being accepted by CI council in the company according to market requirements. It cannot be changed randomly once being determined. Random changes will only give consumers a perceptual process that is not continuous. Consumers will not believe the reliability of products and finally think the products and even the enterprises are "less known and inferior brand" and "low-end".

\section{Enterprises cannot Timely Update the Deficient Visual Identity Elements.}

Visual images in many enterprises (this kind of situation appears more in small and medium-sized enterprises) such as plane advertisement, plaque or neon-light advertisement have become deficient and cannot receive timely update, which is seriously bad for the publicity of enterprise image and also directly influences the display of integral image of the city. Now enterprises have smaller and smaller living space. If they cannot well plan and design their company, fully attract clients and leave people a good and deep impression, then they will be swallowed in the tide of business.

Therefore, the visual identity design of enterprises is an important tool that needs to be used in expressing the management system and external image of enterprises and it is the bridge and bond to connect enterprises with the masses VI in enterprises has the same position as enterprise management and marketing. Three of them supplement and promote each other. Not a single one can be omitted.

\section{ENTERPRISE VISUAL IDENTITY DESIGN IS OUT OF KEEPINGWITH URBAN ECONOMIC DEVELOPMENT}

In order to let enterprise visual identity design adapt to urban economic development, we can take the following measures:

\section{A. Attach More Importance to Development of Visual Identity Design}

Pay attention to VI development of enterprises; give designers enough material guarantees, that is to say enterprises should give basic construction investments including designing room, fixed-asset investments, including equipments, materials and tools related to design; give enough circulating funds including salaries, benefits, bonuses and traveling expenses of designers; give designers certain rights including the decision-making power to lead other people to design and use the market VI scheme.

\section{B. Strive to Improve Comprehensive Quality of Designers}

Nowadays, after people's material living standards are met, they demand the quality of spiritual life can be improved continuously. When people buy products, they always pay attention to the artistry of the product packaging. Walking on the street, they hope the commercial advertisements are creative and fashionable, which is pressing for designers to design through going deep into the society and get close to reality, life and the masses, keep pace with the times in practice, blaze new trails in a pioneering spirit and design works that can meet people's growing, various and multi-level spiritual aes thetic needs.

\section{Specific Implementation Methods of Contents of Visual Identity Design}

In order to do better in visual design of enterprises to better show urban image, the specific implementation methods include:

1) Visual identity design must insist focusing on mind identity.

2) In the process of designing, they should seize ground rules of visual identity design.

Firstly, the design should meet the requirements of people who strongly yearn for spiritual comfort and relaxed 
spirit and call emotional regression and pay attention to the manifestation of humanity.

Secondly, the shape and spread of enterprise image should be designed according to different ethnic culture.

Thirdly, in order to let the enterprise visual identity image reach the best communicating effect and achieve very high memory values and leave deep impressions in the mind of people, it is necessary to notice the design philosophy of simplification in design.

Lastly, visual identity system has aesthetic nature. But more important, it should be able to effectively implement and apply, and pay attention to the applicability of each design project.

\section{Grasp the Fields of Visual Identity Design}

The fields of visual identity design include the system of basic elements and the system of applicable elements.

\section{System of basic elements:}

The first is the name of enterprise, which must reflect the ideas about business operation and embody business philosophy; should be unique, easy to be recognized and read, pay attention to the pronunciation and meaning of partial tone to avoid inappropriate as sociations.

The second is the logo of enterprise. When designing the logo, designers should pay attention to the leading feature, identity, epochal character, formative nature, extensibility, systematic character, aesthetic character, distinctive character and transmission character of the logo. The conception should be artful. In the process of logo design, they must notice the effective application of constitution forms such as symmetry, balance, repetition, harmony, contrast, reflection and gradual change, etc. The logo design should be standard and have good promotional effects.

The third is the standard font of enterprise. Standard font is one of the basis elements in enterprise identity system and it designs unique fonts for the enterprise. Standard font also should notice the distinctive character, formative nature, readability, extensibility and partial compositionality in visual identity system.

The fourth is enterprise standard color. It is an important part of visual identity and shows business philosophy of the enterprise or quality of products through the feelings of color to stimulate psychic reaction. In order to highlight characteristics of the enterprise in market competition, they should choose distinctive colors or combination of colors to reach the goal of highlighting the images. The enterprise standard color should conform to the color of products or packaging, which can create harmonious and unified commodity features.

The fifth is the modeling of enterprise. It should reflect business philosophy and product features, diagrammatize enterprise character or product quality and conform to enterprise spirit. Besides, it should grasp the criterions such as relatedness, individuation, finalize the design, get good name, exaggerated manifestation and simple modeling.
The sixth is symbolic graph. It is a kind of pattern or effect and attached visual identity element that is designed to effectively strengthen the integral image and foil atmosphere and strengthen visual impact, and foil other basic elements in practical design. Symbolic graph uses abundant and various modeling symbols, supplementary markings and standard fonts to make the enterprise image more complete and easier to be identified. In addition, it can also strengthen the visual perception and create primary and secondary, strong and weak rhythmical images.

The seventh is to appoint printing character. The enterprise should choose one kind or several kinds of special fonts that are coordinated with the general characteristics of the enterprise and printing contents for various printing materials to serve as banner words and normal fonts of printing materials such as advertisements and documents, in order to highlight the unique characteristics of the enterprise. These fonts are not specially designed, but chosen from the universal printing characters. When determining frequentlyused printing characters, they should pay attention to that it should be corresponding to standard fonts, but it will lead to blankness if they are excessively approximate. It is better to choose frequently-used fonts, such as boldface, Song typeface, Gulim, variety font, instead of excessively complicated and fancy fonts.

The ninth is the combination of basic elements. The objects in practical application of enterprise are diversified. In combination of symbols and elements, except for frequently-used characteristic combination, it should also include different forms of combination such as the combination of left and right, upper and lower combination and vertical combination, etc.

\section{System of applicable ele ments:}

The first is office supply. Office supplies mainly include: business card, envelope (domestic and international), writing paper, memo, flag of company, security, testimonials, letter of thanks, statement, work certificates, folders, notebooks, badges, invitation card, letter of introduction, official document table, pen, writing case, and ashtray and teacup in reception room. It is difficult for office suppliers with inadequate individuality to leave deep impression on people. Putting new, unique, concise and clear design, symbol and words in full position will not give people the chaotic feeling. On the contrary, it will form the serious, complete, accurate and unified style of office suppliers and give people new feelings.

The second is signboard and logo. Signboard and logo are the first appearance of enterprise. A signboard with strong attraction always has obvious recognition function. It is an important medium to attract and guide customers and can arouse their keen interest. The signboard and logo include the signboard of company, architectural appearance, indications of exit and entrance, signboard of activity, window display, road sign and various nameplates.

The third is communication media. Communication media is the advertising media of activities with less investment and high efficiency. Many enterprises pay more 
and more attention to making use of communication media to increase advertising area and advertising frequency. As a kind of mobile and open mode of transmission of enterprise image, it can repeatedly strengthen people's immediate me mory when people look at it, which help to establish clear enterprise image.

The fourth is gift of public relations. Gifts of public relations are also the mediu $\mathrm{m}$ for enterprises to publicize and make friendly contacts with internal and external parties. Using gifts to publicize enterprise image is also a good method. Therefore, it is also necessary to label image elements of the enterprise on the packaging, such as the name of firm and corporate logo.

The fifth is product display. Commodity shows not only itself, but also embodies the aesthetic taste and level of enterprise. Because most show places are rented or rebuilt and they display products of other enterprises as well, it is necessary to use powerful visual identity means to unify the style. The standard color and symbolic pattern are often the effective tools. The designs of exhibition stand, exhibition position and exhibition room have individuality and the dispose of color space should be striking. Sales brochures, technical data, operation instruction and catalogues should be all in readiness.

The sixth is staff's clothing. Unified costume is effective means to make employees in the enterprise have a sense a belonging. Internally, it can enhance employees' senses of responsibility and constraining force, and then make them establish sense of honor and sense of ownership for enterprise, improve employee morale, change their spiritual outlook and promote the improvement of work efficiency; externally, it embodies the management level and cultural literacy of enterprise, and shows the spiritual outlooks of employees and the enterprise.

\section{CONCLUSION}

To sum up, enterprises without visual identity system will be rapidly swallowed by the competition. After enterprises lead in visual identity, it will make enterprises create vigorous and strenuous strong atmosphere, and make employees feel the civilization of modern enterprises, receive subtle education and improve civilized behaviors. The level of enterprises civilization will directly show urban civilization development. There is no doubt that it has important theoretical meaning and actual application values in excavating rich cultural and artistic resources in China and developing socialist culture with Chinese characteristics and urban civilization, carrying forward our culture, and improving the influences and competitive force of socialism and advanced culture in the city.

\section{REFERENCES}

[1] Jiang Zhusong, Baylee, C Design Basis and Creativity [M], Beijing: China Textile Press, 2006

[2] Xiao Yong, Liu Dongtao, Tu Ya. VI Design Patter [M], Beijing: Higher Educat ion Press, 2008
[3] Mao Feng. VI Design Basis [M], Nanjing: Jiangsu Fine Arts Publishing House, 2007

[4] Zhou Xu, Luo Shijian. Corporate Image Design [M], Beijing: Higher Education Press, 2006

[5] Liu Fei, Research on Color in VI Design [J], Grand Stage, 2010 (10)

[6] Cao Shenggong. CIS Design [M], Nanjing: Southeast University Press, 1999 